\title{
Effects of Propolis on Spatial Memory Induced by Lithium Pilocarpine in the Experimental Status Epilepticus Model in the Rats
}

\author{
Gül Büşra Kaya ${ }^{1}$ Memet Hanifi Emre ${ }^{2}$ \\ 1. Inonu University, School of Medicine .Department of Physiology. Malatya/Turkey \\ 44280 \\ 2. Bahcesehir University School of Medicine ,Department of Physiology . Göztepe-Kadıköy/ Istanbul/Turkey
}

34734

\begin{abstract}
Status epilepticus (SE) is a common neurological disorder with repeated convulsions that persist for 30 minutes or longer in children and the elderly, leading to neuronal damage in the brain if it is not controlled. The lithiumpilocarpine ( $\mathrm{Li}-\mathrm{Pc}$ ) model of SE is the most suitable and frequently used method for pathophysiological changes of SE.
\end{abstract}

Keywords: Status epilepticus, propolis, spatial memory, hippocampus, Morris water maze.

DOI: $10.7176 / J N S R / 9-18-01$

Publication date:September $30^{\text {th }} 2019$

\section{Introduction}

Epilepsy is a neurological disease characterized by spontaneous seizures caused by focal or generalized paroxysmal changes in neurological function by abnormal activity in the cortex. It affects approximately $1 \%$ of the world population. It is a common and serious neurological disorder. (Ahl et al.2016). The incidence of epilepsy in childhood and elder ages was observed at the highest levels (Seino 2006, Ahl et al.2016, Alverez -Croda et al. 2016, Scorza FA, et al.2009). Epilepsy affects around 50-70 million people in the world and 20-30\% of them have seizures that cannot be controlled with every day anti-epileptic drugs (Marangoz 1997, Akpınar 2014).

Although many studies have been done on this subject, the underlying mechanism of epilepsy is still unclear. Since the etiology of epilepsy varies, it may arise due to a brain infection, trauma, ischemia, tumor, neurodegenerative disease or genetic disposition (Ahl et al.2016, Scorza FA, et al.2009, Abad RS-C etal. 2007, Tian Q, et al.2016). Epilepsy is a serious neurologic disease and there are a lot of numbers type of seizures. We are especially interested in status epilepticus. the status epilepticus is a special type of epilepsy which is characterized by a lasting seizure 30 minutes. Status epilepticus is a type of epilepsy which is threatening of life and regarded emergency with considerable mortality and morbidity. Although there is a controversy about the duration of seizures in the status epilepticus among researchers, status epilepticus is a disease characterized by a single seizure activity lasting 30 minutes or longer. (Akpınar 2014, Su J et al.2015, Maytal 1989, Tatlı et al 2005, Shinnar et al.1992). SE is a disease that must be diagnosed and treated quickly both because of being lifethreatening and causing serious neurological damage (Alverez -Croda et al. 2016, Shinnar et al 1992).

In the brain of people with epilepsy, CA1 and CA 3 neurons and maybe CA2, CA4 neurons in the hippocampal region, are considered to be "pacemaker" centers. Especially, some part of the hippocampal area (such as the CA1, CA3 areas, and dentate gyrus) is the most vulnerable region to neuronal damage produced by lithium-pilocarpine. It was detected that it is especially neurodegeneration in the CA1 and CA3 areas (Alverez -Croda et al. 2016 Zaidel et al .1993,Ahmad M 2013). These areas in the hippocampus are the areas that play the most active role in learning (Ahmad M 2013, Vorhess et al.2006,McCormick et al.2003). Therefore, researchers have concentrated on these areas of the hippocampal slices. Thus, damages that occur in these areas after epileptic seizures affect learning negatively (Alverez -Croda et al. 2016, Zaidel et al .1993, Ahmad 2013, Alaa et al.2018).

Propolis is a resinous substance that is obtained from honey bees. It is known that it has anti-microbial, antioxidative, antiviral, antifungal and anti-tumoral properties. Propolis contains polyphenol (flavonoids, phenolic acids, and other esters) terpenes, a number of chemical components. Through the studies, it has been shown that propolis which has anti-oxidant properties, protects the brain from various neuron based diseases (Khalil ML 2006,Scorcin Jm 2016,Farooqui et al 2012). These findings suggest that propolis may have a significant impact on the prevention and treatment of SE.

Our aim in this study is to detect how status epilepticus, which is more common in older ages and in childhood, affects spatial memory and whether propolis, which has important functional and regulatory effects, has a therapeutic or protective influence on spatial memory in the epileptic process.

\section{Materials and Methods}

In this study, 12-week old 50 Sprague-Dawley female rats of 200-300 grams were used. The rats were divided into 
5 groups:

The experimental animals were kept at $21 \pm 1{ }^{\circ} \mathrm{C}$ temperature and were subjected to 12 -hour light / dark cycles. The rats were expected to get used to each other and the environment in 3 days. The rats were fed ad libitum. The experiment was conducted in accordance with the recommendations of the ethics committee of İnönü University.

\subsection{Preparation of propolis}

The Propolis used in the present study was collected from hives located in the rural of Anatolia and prepared to according to Alves de Lima et.al (2005). Dissolved substances were put into volumetric glass flasks and kept in the refrigerator at $+4^{\circ} \mathrm{C}$.

Animal of the experimental groups (second, third and fourth) was administered $0.012 \mathrm{mg} / \mathrm{kg}$ the extract of propolis each day.

\subsection{Induction of Status epilepticus by lithium and pilocarpine}

All experimental groups of animals, except the control group, received lithium chloride ( $3 \mathrm{mg} / \mathrm{kg}$, i.p. Alfa-Aesar Germany ) $24 \mathrm{~h}$ before the administration of pilocarpine, and plus except control group, all experimental groups of animals were administered $30 \mathrm{~m} / \mathrm{kg}$ pilocarpine dose i.p (Alfa-Aesar -Germany Li LY et al 2013). Behavioral assessment of seizure was evaluated according to the Racine scale, the animals were considered to have progressed on to SE when stage $\mathrm{V}$ was observed. video record was used to for behavioral assessment for first hours after pilocarpine injection. the scoring was based on the Racine Scale as described by Racine with following stages: (0), no abnormality; (1), mouth and facial movement,(2), head nodding; (3), Forelimb clonus; (4), Rearing ; (5),Rearing and following.(Druga et al 2003, Costa -Ferro et al . 2014). Diazepam (25mg/kg) i.p.) was administered 30 min after the onset of SE, to block seizure(Qashu et al. 2010).

\subsection{Experimental groups}

The following experimental groups were studied;

Group 1: (n10) Control group

Group 2 (n10) Propolis extract, 0.012 g / kg + (after 1 week) + lithium 125 mg / kg i.p (after 24 hours) + pilocarpine $25 \mathrm{mg} / \mathrm{kg}$ i.p

Group $3(\mathrm{n}=10)$ Lithium + pilocarpine diazepam $(5 \mathrm{mg} / \mathrm{kg})+$ propolis extract

Group $4(n=10)$ Lithium + pilocarpine + propolis extract

Group $5(\mathrm{n}=10)$ Lithium + pilocarpine (epileptic group)

The rats were anesthetized with intraperitoneal ketamine $(90 \mathrm{mg} / \mathrm{kg})$ and Xylazine $(10 \mathrm{mg} / \mathrm{kg})$ and the end of the procedures animals were sacrificed .Emre et al.2009).

\subsection{Morris water maze}

The Morris water maze was developed in 1984 by Richard G Morris for the evaluation of visual-spatial learning in animals. It also has been used to assess the cognitive function of the variety of epilepsy models in the animals. It is a circle pool and size of it may change according to animals used to in the experimental. It was filled with clear tap water $\left(22 \pm 1{ }^{\circ} \mathrm{C}\right)$ before starting the experiment. the platform which stainless steel, was placed $2 \mathrm{~cm}$ below water level and the water was made opaque by the nontoxic paint the addition which prevented visualization of the platform (Mixol- Diebold GmbH- Germany).the surface is covered with a cloth to make it easier for animals to hold onto the platform. Four points on the rim of the tank were designated north, south, east and .west. Thus dividing the pool into four quadrants. some geometric shapes were attached to the walls of the room so that the experiment animals could learn the poles of the Morris water maze (Vorhees et al.2006, Morris 1984).

Experimental animals were subjected to four trials a day for 5 days, and a platform is taught in an invisible pool (Vorhees et al.2006, Morris 1984). Their performances in 4 days enable us to evaluate the working memories of the subjects. The platform is removed from the pool for recall test on the 5 th day and reference memory is evaluated by recording the time the subject spends in the quadrant where the platform is located (Vorhees et al.2006, Morris R 1984)

\subsection{The period for adjusting the rats to the Morris water maze}

To monitor, record and analyze the movements of the rats in the maze, a computerized video camera system (Ethovision, Noldus) was used. The paths on the first 4 days of the learning process of a rat in the Morris water maze and on the $5^{\text {th }}$ day probe-test are shown in Figure1. 

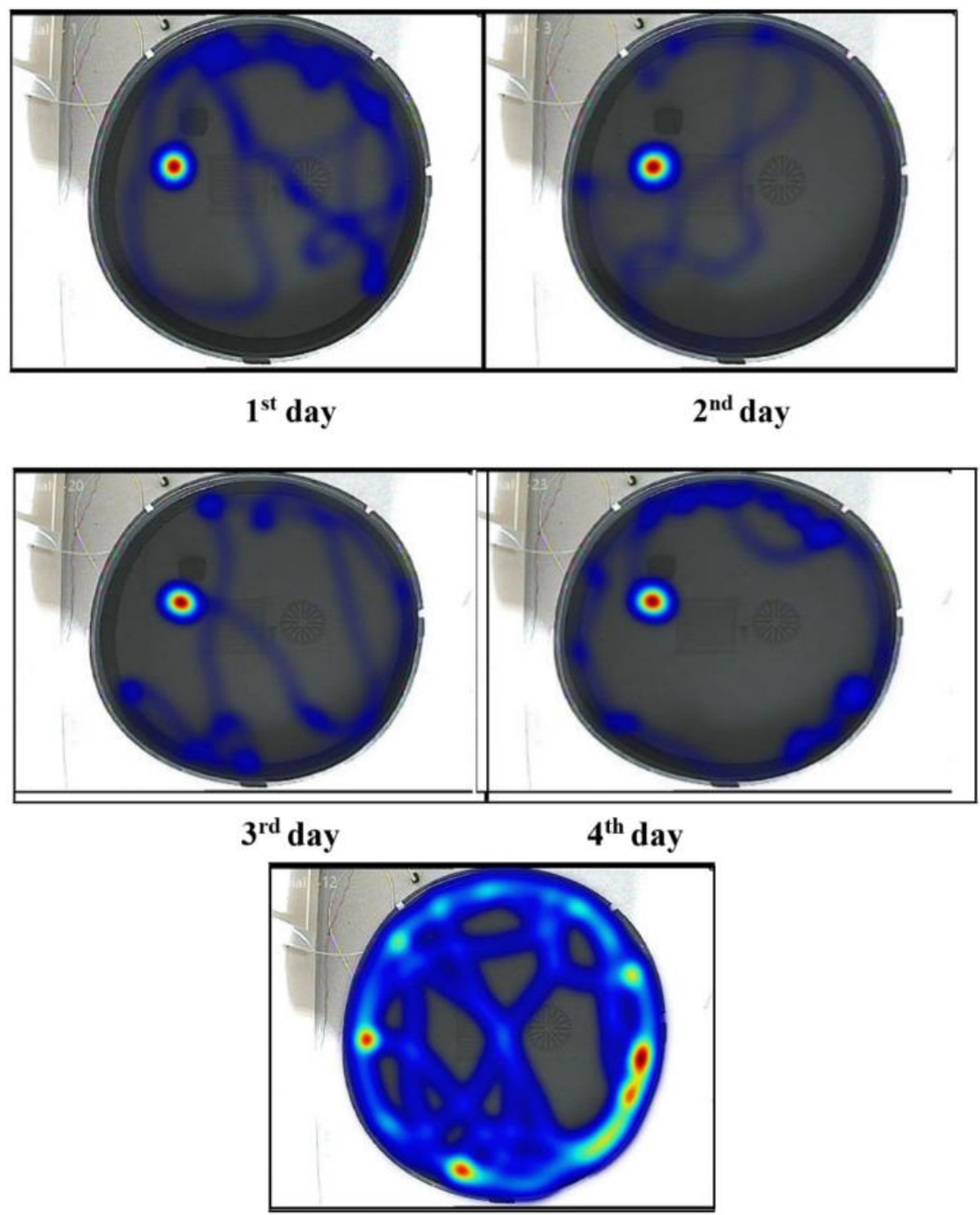

\section{$5^{\text {th }}$ day (Probe-test)}

Figure 1. The paths on the first 4 days of the learning process of a rat in the Morris water maze and on the 5th day probe-test.

\subsection{Morris water maze spatial memory test data of the test groups after SE}

While giving Lithium-pilocarpine to the experiment groups and monitoring the status epilepticus seizures in rats, the Morris water maze learning test, which was performed on the same day before the experiment, was performed after creating the experimental models. Except for the control group, each rat was allowed to swim for 4 times from 4 different quadrants in the Morris water maze. The time the rats spent in the quadrant, their time reach to the platform and their distance to the platform were measured and recorded by a video camera system in Figure 2 . 


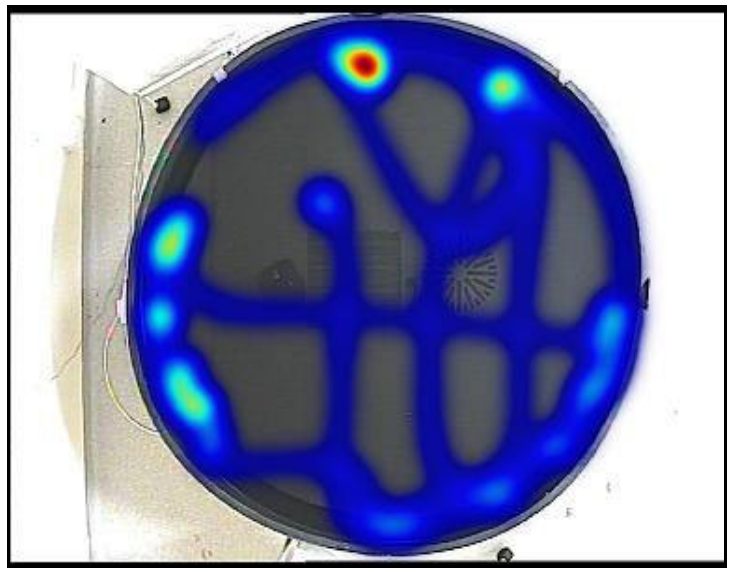

Figure 2. The path of an epileptic rat in a Morris water maze.

After all the processes, aqueous propolis extract was given every day via oral gavage to the 3rd and (the) 4th groups for a month. The extract was strictly administered at the same hours each day. This operation was performed on only two groups and was monitored with the aim of determining the protective or therapeutic efficacy of propolis with respect to time as well as determining the differences with respect to the other groups within this time.

\subsection{Morris water maze test data for the experimental groups which were given propolis}

After giving propolis via oral gavage for 1 month to the $3 \mathrm{rd}$ and 4 th experimental groups, the Morris water maze test was performed once again, in order to determine the changes that occurred in the learning and memory of these groups. Images were recorded by a video camera system in Figure 3.
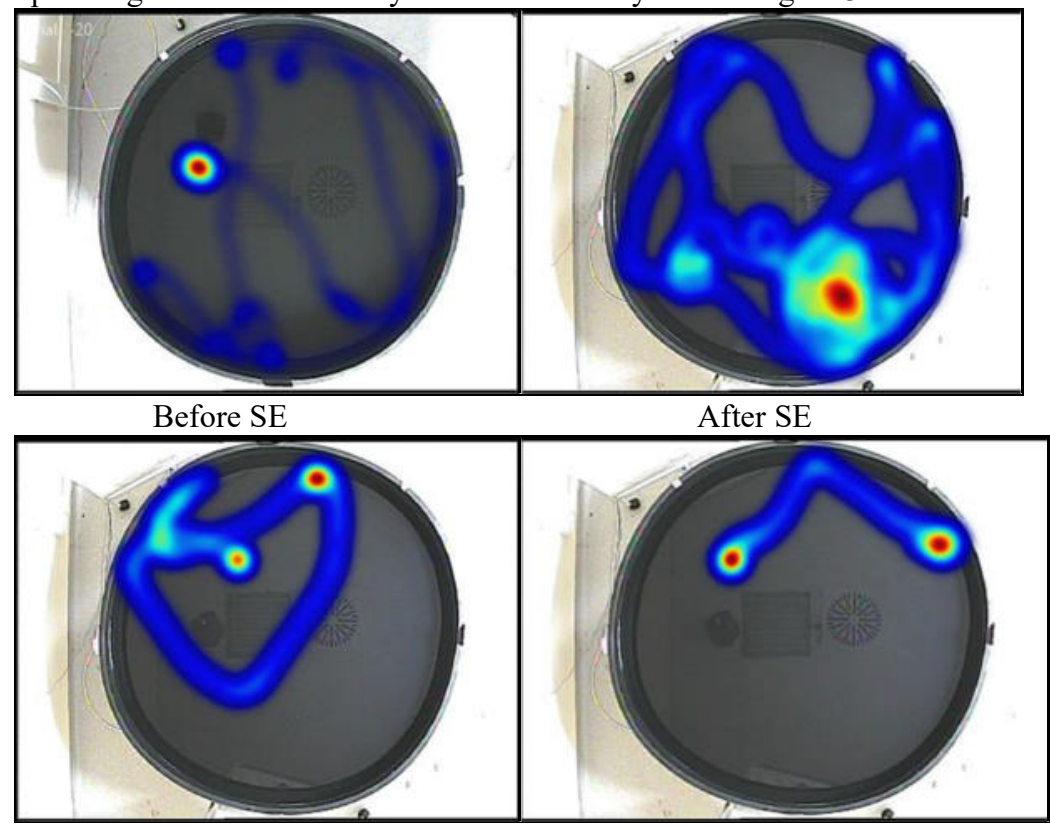

Before Propolis

After Propolis

Figure 3. Comparison of propolis given period with seizures.

\subsection{Histological Assessment}

The hippocampus tissues gained at the end of the experiment were identified in $10 \%$ formaldehyde. The tissues were washed in tap water and eventually, they were embedded in paraffin blocks after the dehydration and polishing processes.

4-5 $\mu \mathrm{m}$ thick sections were taken from the paraffin blocks. Deparaffinization and rehydration processes were performed. Then, hematoxylin-eosin (HE) staining method was applied to the sections (Suvarna et al 2012). Stained preparations were analyzed by a Leica DFC-280 research microscope.

A Leica Q Win image analysis system of $40 \mathrm{X}$ amplification was used to evaluate the degenerative changes 
in neurons and neuron loss in the hippocampus pyramidal layer (in the cytoplasm and nucleus) for each of the preparations. According to this; the degree of damage was scored as; 0: solid, 1: mild, 2: moderate, 3: severe. (Brywe,et al 2005, Sharma et al. 2008).

\subsection{Statistical analysis}

Statistical analysis was performed using SPSS 12.0 for Windows software. The Data were expressed as the mean \pm standard error. The quantitative data related to these variables do not show the normal distribution and were tested by the Shapiro-Wilk normality test $(\mathrm{p}<0.05)$.

For the comparison of data between the groups that were subjected to the Morris water maze test, the MannWhitney $U$ test was used. It was considered statistically significant $(\mathrm{p}<0.05)$. Histological findings for the evaluation of statistical analysis were performed with SPSS statistical software (SPSS for Windows version 17). All data were expressed as arithmetic mean \pm SD. Mann-Whitney U test was used for comparisons between groups. It was considered to be significant $(\mathrm{p}<0.05)$.

\section{Results}

\subsection{Morris water maze test results before the experiment}

Before applying the experimental protocol, the rats were trained for four days and during this protocol, the time the rats in all groups spent in the quadrant and the distance to reach the platform were measured.

In the Morris water maze test exercises, the time they spent in the quadrant for all the groups is shown in Table 1. Although the time of stay in the quadrant was short for all groups on the first day, it was established that there is a significant increase in the time of stay in the quadrant on the $2 \mathrm{nd}, 3^{\text {rd }}$ and $4^{\text {th }}$ days $(\mathrm{p}<0.05)$. It was detected that the time that rats spend in Southwestern quadrant (SW), where the platform is, increases on the 2nd, $3 \mathrm{rd}$, and 4 th days $(\mathrm{p}<0.05)$.

When results for all groups from probe-trial test, where the quadrant was removed, were compared with the results of the first 4-days, it was found out that the time to reach the platform on 5 th day decreases and, the time spent in the quadrant increases as compared to the other days $(\mathrm{p}<0.05)$.

Table 1.The time spent in the quadrants before Morris water maze for all groups (mean \pm standard error)

\begin{tabular}{|l|l|l|l|l|}
\hline Days & Northwest (NW) & \multicolumn{1}{|c|}{$\begin{array}{c}\text { Northeast } \\
(\mathbf{N E})\end{array}$} & $\begin{array}{c}\text { Southwest } \\
(\mathbf{S W})\end{array}$ & $\begin{array}{c}\text { Southeast } \\
\text { (SE) }\end{array}$ \\
\hline 1s t day & $1.93 \pm 0.16$ & $2.43 \pm 0.17$ & $2.72 \pm 0.14$ & $3.65 \pm 0.12$ \\
\hline $\begin{array}{l}\text { 2nd, 3rd, and 4th } \\
\text { days }\end{array}$ & $2.56 \pm 0.083$ & $3.07 \pm 0.37$ & $4.63 \pm 0.16$ & $2.46 \pm 0.06$ \\
\hline 5th day & $6.26 \pm 0.33$ & $5.24 \pm 0.26$ & $6.32 \pm 0.28$ & $5.44 \pm 0.31$ \\
\hline
\end{tabular}

Table 2. The paths before Morris water maze test exercises and 5th day of probe trial tests for all groups (mean \pm standard error $* \mathrm{p}<0.05)$.

\begin{tabular}{|l|l|}
\hline Days & $\begin{array}{l}\text { The path took for target quadrants } \\
(\mathbf{c m})\end{array}$ \\
\hline 1s t day & $1572.09 \pm 51.55$ \\
\hline 2nd, 3rd and 4th days & $855.6 \pm 26.9^{*}$ \\
\hline 5th day & $245.9 \pm 16.85^{*}$ \\
\hline
\end{tabular}

\subsection{Evaluation of results of the Morris water maze test after the experiment}

After the test protocols applied, the results received from the Morris water maze test were compared for all groups. In the test, the time spent by the rats in each quadrant, the latency to reach the platform and the paths to reach the platform were evaluated separately.

The time spent in the Morris water maze test quadrants by the control group, the epileptic and propolis group is shown in Table 3. Time of stay in the quadrant of the rats in the epileptic group (Group 5) was found out to be significantly shorter than the other groups. $(* p<0.05)$. 
Table 3. The time spent by the control group, having SE and propolis group in quadrants (mean \pm standard error).

\begin{tabular}{|l|l|l|l|l|}
\hline Groups (n=8) & $\begin{array}{l}\text { Northwest } \\
(\mathbf{N W})\end{array}$ & $\begin{array}{l}\text { Northeast } \\
(\mathbf{N E})\end{array}$ & $\begin{array}{l}\text { Southwest } \\
\text { (SW) }\end{array}$ & $\begin{array}{l}\text { Southeast } \\
\text { (SE) }\end{array}$ \\
\hline Control & $5.25 \pm 0.14$ & $6.60 \pm 0.121$ & $6.80 \pm 0.132$ & $5.65 \pm 0.16$ \\
\hline Propolis+lithium+pilocarpine & $2.32 \pm 1.71^{* *}$ & $1.07 \pm 0.36^{* *}$ & $2.19 \pm 0.89^{* *}$ & $1.24 \pm 0.12^{* *}$ \\
\hline Lithium+pilocarpine+diazepam+propolis & $3.23 \pm 0.59$ & $3.12 \pm 0.34$ & $3.49 \pm 0.52$ & $2.52 \pm 0.61$ \\
\hline Lithium+pilocarpine +propolis & $3.1 \pm 0.61$ & $3.21 \pm 0.41$ & $4.42 \pm 0.12$ & $2.23 \pm 0.32$ \\
\hline Lithium+pilocarpine (epileptic group) & $0.31 \pm 0.08^{*}$ & $0.42 \pm 0.15^{*}$ & $0.2 \pm 0.12^{*}$ & $0.41 \pm 0.16^{*}$ \\
\hline
\end{tabular}

Table 4. The time spent in the quadrant by the SE and propolis groups (mean \pm standard error)

\begin{tabular}{|l|l|l|l|l|}
\hline Quadrants & \multicolumn{1}{|c|}{$\begin{array}{c}\text { Northwest } \\
(\mathbf{N W})\end{array}$} & \multicolumn{1}{|c|}{$\begin{array}{c}\text { Northeast } \\
(\mathbf{N E})\end{array}$} & $\begin{array}{c}\text { Southwest } \\
\text { (SW) }\end{array}$ & \multicolumn{1}{c|}{$\begin{array}{c}\text { Southeast } \\
\text { (SE) }\end{array}$} \\
\hline All groups after SE & $2.60 \pm 0.133$ & $2.65 \pm 0.16$ & $1.80 \pm 0,13$ & $2.25 \pm 0.14$ \\
\hline Propolis groups & $3.12 \pm 0,16$ & $3.41 \pm 0.18$ & $3.54 \pm 0,23 *$ & $3.20 \pm 0.51^{*}$ \\
\hline
\end{tabular}

Diazepam was injected to the rats in order to stop the seizure activity, (Group 3 ) and then, propolis was given by oral gavage. But the seizure activity wasn't stopped in group 4 and propolis was given by oral gavage directly. These two groups were compared in terms of the time of stay in the quadrants. There was no statistically significant difference between them. $(\mathrm{p}>0.05)$. When the 3rd and 4th groups were compared with the 2 nd group in terms of the time of stay in quadrants, the time of stay of the 2 nd group was significantly lower than the $3 \mathrm{rd}$ and 4 th groups and significantly longer than the epileptic group (5th group) $(* p<0.05)$. (Table 4$)$. As shown in Table 5, the latency time to reach the platform and distance covered in the platform for the 3rd and 4th groups were found to be significantly shorter than for group $2(* \mathrm{p}<0.05)$.

Table 5. The latency time to reach the platform and distance covered in the platform of SE and propolis groups (mean \pm standard error).

\begin{tabular}{|l|l|l|}
\cline { 2 - 3 } \multicolumn{1}{c|}{} & All groups after SE & Propolis groups \\
\hline $\begin{array}{l}\text { Latency to reach } \\
\text { the platform (sec) }\end{array}$ & $34.8 \pm 3.76$ & $30.5 \pm 2.66^{*}$ \\
\hline $\begin{array}{l}\text { Distance covered in the } \\
\text { platform(cm) }\end{array}$ & $37719.5 \pm 2160.91$ & $35033.7 \pm 1897.9^{*}$ \\
\hline
\end{tabular}

\subsection{Histologic Results}

In the sections of the control group, neurons located in the pyramidal layer were observed to have normal morphology. These neurons have round, large and euchromatic nuclei. Since the cytoplasm is painted in bright colors, it could not be clearly distinguished from the boundaries of neuronal cell bodies in Figure 4, A.

The decrease in neuronal density and neuronal degenerative changes were observed in the G5 group. It was observed that many of neurons in this group underwent necrosis.

Necrotic neurons, cytoplasm with shrunken and increased acidophility were distinguished by dark-colored pyknotic nuclei in Figure 4, B and C.

Necrotic neurons were rarely observed in G2, G3 and G4 groups in Figure 4, D, E, and F. Necrotic neurons were seen the most distinctly in the G2 group. The least neurodegenerative changes were detected in the G4 group. On the other hand, histopathological scores in the propolis group were found as significantly decreased when compared to the G5 group, $(\mathrm{p}<0.05)$. 


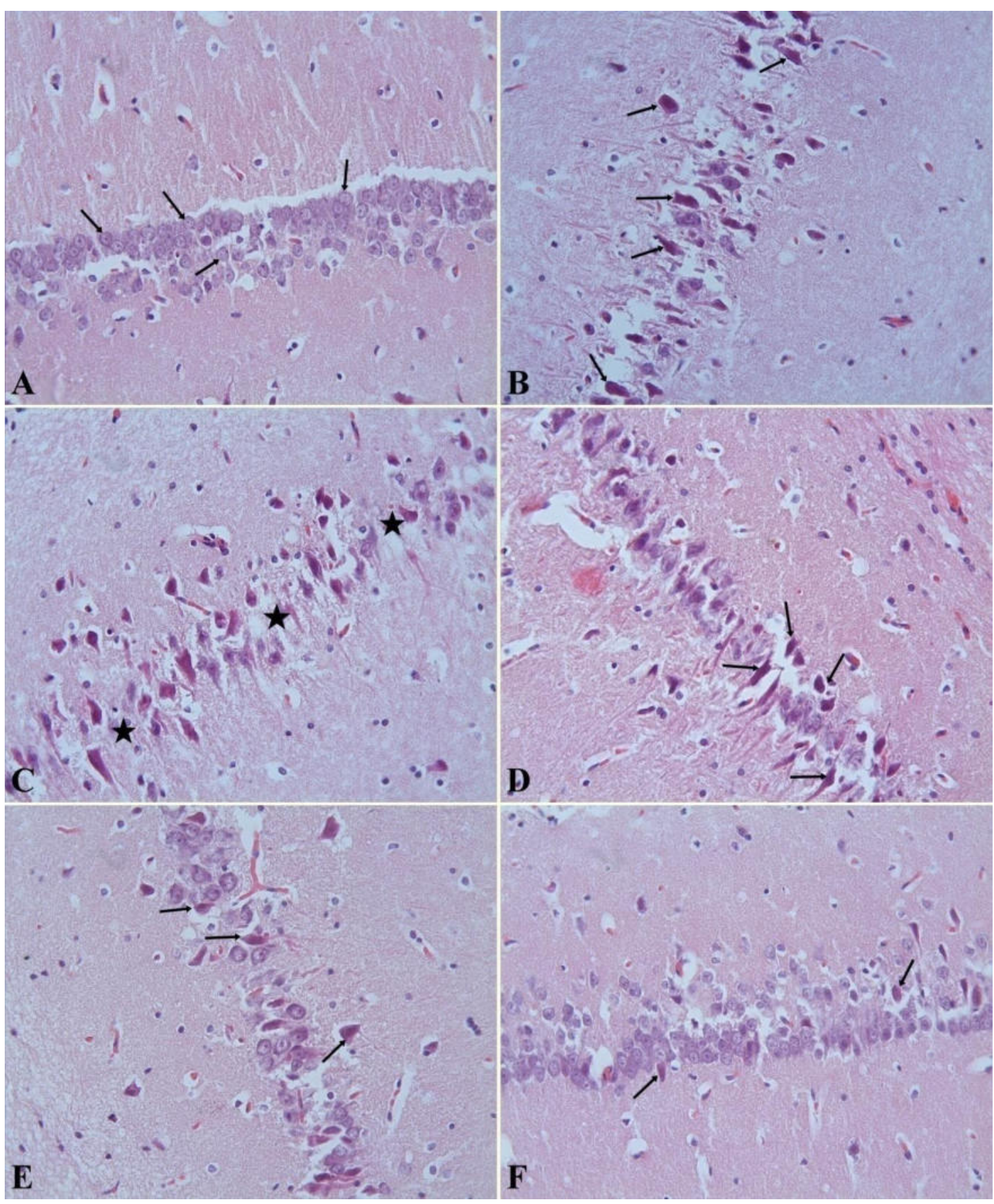

Figure 4. (Control Group); The histological appearance of normal pyramidal neurons observed (arrows), B (G5 Group); Necrotic neurons, cytoplasm with shrunken and increased acidophility and distinguished by dark colored pyknotic nuclei (arrows), C (G5 Group); reduction in neuronal density (asterisk), D (G2); is observed to persist necrotic neurons (arrows), E (G3 Group) and F (G4 Group); necrotic neuronal density (thick arrows) decreases. H-E X40.

Tablo 6. Histopathological score of groups.

\begin{tabular}{llllll}
\hline & Kontrol & G5 & G2 & G3 & G4 \\
\hline $\begin{array}{l}\text { Histopathological } \\
\text { Score }\end{array}$ & $0.55 \pm 0.60$ & $2.25 \pm 0.78^{\mathrm{a}}$ & $1.88 \pm 0.62^{\mathrm{b}}$ & $1.50 \pm 0.93^{\mathrm{b}, \mathrm{c}}$ & $1.23 \pm 0.89^{\mathrm{b}, \mathrm{c}}$ \\
\hline
\end{tabular}

a. Statistically, a significant increase when compared to the control group $(\mathrm{p}<0.05)$.

b. Statistically, significant decrease when compared to the G5 group $(\mathrm{p}<0.05)$. c.

Statistically, significant decrease when compared to G2 $(\mathrm{p}<0.05)$. 


\section{Discussion}

\section{The Effects of propolis on learning and spatial memory}

According to the results of this study, it was determined that propolis reduced the oxidative stress which increased the production of reactive oxygen species but it also increased the protective mechanism of the neuronal cells, which is sensitive to the harmful effects of lithium-pilocarpine.

After experimental SE model was created, the Morris Water Maze test protocols were applied to rats of the experimental groups. The results of all the groups were compared. The time of stay of the rats in the quadrant was found to be significantly shorter in the epileptic group (Group 5) $(* p<0.05)$ when compared to control group and the groups that were given propolis $\left(3^{\text {rd }}\right.$ and $4^{\text {th }}$ groups). On the other hand, the path and the time spent to reach the platform was statistically significantly longer in group 5 than the other groups.

This result was consistent with the histological score because lithium-pilocarpine induced serious damage to the hippocampus, especially in the CA1 and CA3 areas of the epileptic group. table. 6 . Therefore, the rats in the epileptic (group 5) traveled a longer path to arrive at the platform than the other group, because there were several neuronal losses in group 5.

Differences in the findings of the study groups recorded from both Morris water maze and histological scores showed that propolis has therapeutic effects against the harmful effects of lithium-pilocarpine.

Status epilepticus (SE), due to seizure activity longer than $30 \mathrm{mins}$, is known for its negative impacts on neuronal and psychosocial development during childhood and older age (Akpınar 2014,Su et al. 2015 Maytal et al.1989, Tatl et al 2005,Shinnar et al 1992). This situation brings along the learning disability. Many studies on epilepsy have shown that neuronal losses have occurred especially in the CA1, CA3 regions of the hippocampus, the dentate gyrus, and the amygdale that have led to disorders of learning and memory (Zaidel et al 1993CostraFerro et al.2014,Bertram 2009, Müller et al.2009).

Propolis has been used in medicine in different parts of the world for a long time. It is a resinous substance that is obtained from honey bees; it is a substance known to have anti-microbial, anti-oxidant, antifungal, antiviral and anti-tumoral properties. In studies, especially considering the antioxidant properties of propolis, it has been shown that it protects the brain against a variety of diseases of neuronal origin such as MS and Alzheimer's (Khali 2006,Scorcin 2016,Farooqui et al.2012,Inokuchi et al.2006,Ni et al. 2017). It makes us think that propolis may have an effect so as to heal the damages of SE on learning and spatial memory and it may also have protective effects against $\mathrm{SE}$.

Many studies have been done on the effect mechanism of propolis. However, the effect mechanism of propolis has not yet been completely understood because the chemical composition of propolis contains 300 different substances such as flavonoids and phenolic acids. Therefore, the protective effect of propolis can be obtained through different mechanisms. For example, free oxygen radicals can be removed from the environment or the production of free oxygen radicals may be reduced, etc.( Khali 2006,Scorcin 2016,Farooqui et al.2012,Emre et al 2009, Inokuchi et al.2006, Ni et al. 2017, Bankova et al 2018,Pasupuleti et al 2017).

Although there are many studies about propolis' effects on epilepsy, not all of them include its effects on learning and memory regarding people with SE. In our study, rats in all groups were compared after creating SE experimental models and control groups by using the Morris water maze and the changes that have occurred in spatial memory were evaluated. Our findings support the reported findings on literature (Khalil 2006,Farooqui et al.2012, Inokuchi et al.2006, Ni et al. 2017). In addition, we evaluated whether propolis was effective on the damages that occur after epileptic seizures on the neurons in the CA1 and CA3 sections of the hippocampus or not.

In the Morris water maze test exercises, the time spent in the quadrant of all groups is shown in Table 1. On the first day, while the time spent in the quadrant was short for all the groups, it was seen that there was a significant increase in the time of stay in the quadrant on the $2 \mathrm{nd}, 3 \mathrm{rd}$ and 4 th days $(\mathrm{p}<0.05)$. It was also detected that the rats spent more time on the $2 \mathrm{nd}, 3 \mathrm{rd}$, and 4 th days in the southwestern (SW) quadrant, where the platform is located $(\mathrm{p}<0.05)$.

When the results of all groups from probe-trial memory test when the platform was removed on the 5th day, were compared with the results of the first 4-days of training period, it was found out that the path to reach the platform was shorter and the time spent on the target quadrant was longer on the 5 th day, $(\mathrm{p}<0.05)$. Table 1 . The difference between the findings at this stage of the study reflects between the working memory and the reference memory which obtained via training.

After the creation of the experimental model of SE, Morris water maze test was performed for all the groups of rats and compared in terms of the time spent in the quadrant. The time spent was significantly longer in the control group and propolis treated group (3rd and 4th group) than in group 5 (epileptic group). Table. three, four and five respectively. On the other hand, the path to reach the platform and the time is taken to reach the platform was significantly longer in the fifth group than in the other groups. Table. four and five. It is possibly because of the damage created by pilocarpine on certain areas in the hippocampus. As noted in the histological sections, another finding which supports this situation is the decrease in epileptic 5th group cytoplasm of neurons, 
acidophilic and pyknotic nucleus which were distinguished by necrotic neurons and neuronal density in the hippocampus (Figure 1 C). Our results show similarities to the results of the other researcher (Alverez -Croda et al 2016, Scorza et al 2009 ,Ahmad 2013, Contreras-Garcia et al.2018 ).

According to the results of the $3^{\text {rd }}$ and $4^{\text {th }}$ groups which were treated with propolis for a month after SE seizures and the $2^{\text {nd }}$ group which was given propolis before the experiment, propolis was detected as being effective on learning and memory. According to the results of the Morris water maze test, the time spent in quadrants for the $3^{\text {rd }}$ and $4^{\text {th }}$ groups were found to be longer than for group 2 and the path and time spent to reach the platform were found to be shorter.table. three and four. The damages that occurred in the hippocampus due to lithium and pilocarpine disappeared in groups (3rd and 4th groups), which were given propolis after an epileptic seizure. Necrotic neurons (Figure 1 D) were monitored in group 2 most obviously, the least neurodegenerative changes were detected in Group 4 (Figure 1 F). It may be considered that propolis has a reducing effect on neurodegenerative changes after seizure activities especially in the hippocampus because of the chemical components it has, such as polyphenols, terpenoids, steroids, amino acids (Ahmad 2013,Khalil 2006, Farooqui et al 2012 Inokuchi et al 2006,Ni et al 2017). However, neurodegenerative changes in hippocampus do not improve significantly in the 2 nd group which was given propolis before the experiment when compared to the $3 \mathrm{rd}$ and 4 th groups. It reveals that propolis has a higher therapeutic efficiency after the seizure rather than protective effects.

According to the epileptic group (Group 5), the time spent in the target quadrant was found to be longer for the rats in the experimental group 2(Table three). Our results show parallelism with the results in the literature in terms of the time spent to reach the platform and the time of stay in the quadrant for both the control group and all the other groups (Ahmad 2013, Müller et al.2009, Faure et al. 2013). On the other hand, according to epileptic group 5, the histopathological scores in the propolis group were found to be significantly reduced (Figure $1 \mathrm{E}$ and F). Possibly, it is thought to be related to the damage created by lithium and pilocarpine in the hippocampus. Also. the density of neurons decreased in the hippocampus. Additionally, neurodegenerative changes in neurons of group 2 in histological sections were observed to decrease statistically significantly when compared to the $5^{\text {th }}$ group. This shows that propolis definitely has a protective efficiency before seizures.

\section{Conclusion}

According to our results, neuronal damage caused by lithium + pilocarpine was repaired by propolis. This is probably achieved by scavenging free radical or reducing the production of free radicals that cause damage to the neuronal cells around them. Our study reveals that if propolis is used as an antiepileptic drug or with an antiepileptic agent, it can be useful in the treatment of SE and can reverse neurological damage. We also want to study the effect of propolis on the different type of epilepsy and different aged of people with epilepsy disease. Therefore, the future research will concentrate to explain on the effect mechanism of propolis.

\section{Acknowledgments}

We would like to thank Dear Adviye Melek Demirdöğen for her contribution in reviewing the article in terms of language and Mr. Mustafa Ünver who provided support for recording the changes in the behavior of animals during the epilepsy process by video-camera system.

\section{References}

1. Seino M., 2006. Classification criteria of epileptic seizures and syndromes.Epilepsy Res 70S,27-33.

2. Ahl M, Avdic U, Skoug C, Ali I., Chugh D, Johansson UE., and Ekdahl.CT., 2016. Immun response in the eye following epileptic seizures. Journal of Neuroinflammation; 13:155,1-15.

3. Alverez -Croda DM, Santiago-Garcia J, Medel-Matus JS, Martinez-Quiroz J, Puig-Lagunes AA, BeltranParrazal L, and Lopez-Mareaz ML.,2016. Hippocampal distribution of IL-1 $\beta$ and IL-1RI following lithiumpilocarpine-induced status epilepticus in the developing rat. An Acad Bras Cienc 88(1)pp 653-663.

4. Scorza FA, Arida RM, Naffah-Mazzacoratti Maria DA Graca,.Scerni DA, Calderazzo L, and Cavalheiro EA.,2009 "The pilocarpine model of epilepsy: what have we learned?" Anais da Academia Brasileira de Ciências 81(3): 345-365.

5 . Marangoz C.,1997. Deneysel Epilepsi Modelleri. O.M.Ü. Tıp Dergisi. 14(3): 147-186.

6. Akpinar CK., 2014. Status epilepticus'un Güncel tanı, tedavi ve etyolojisi”, Epilepsi Vol 20 No.1 pp 1-10.

7. Abad RS-C, Sanmarti Vilaplana FX, and Fernandez, JMS.,2007. Genetic causes of epilepsy.the neurologist 13, n.65, pp 47-51.

8. Tian Q, Xiao Q, Yu W, Gu M, ZHAO N,.Lü Y.,2016. The Inhibition of transforming growth factor BetaActivated kinase 1 contributed to neuroprotection Via Inflammatory reaction In Pilocarpine-Induced Rats with Epilepsy. Neurosciences 325,111-123.

9. Su J, Yin J, Qin W, Sha S, Xu J, and Jiang C.,2015.Role for pro-inflammatory cytokines in regulating expression of GABA transporter type 1 and 3 in specific brain regions of kainic acid-induced status epilepticus. Neurochem Res. 40(3):621-7. 
10. Maytal J, Shinnar S. Moshé SL, Alvarez. LA.,1989 “Low Morbidity, and Mortality of Status Epilepticus in Children.Pediatrics March, Volume 83 323-331.

11. Tatlı B, Soysal D, Çıtak A, Aydınlı N, Üçsel R, Karaböcüoğlu M, ÇalışkanM, Özmen M, Uzel N., 2005 .Çocukluk çağında status epilepticus. Çocuk Sağlığı ve Hastalıkları Dergisi 48:290-294.

12. Shinnar S, Maytal J, Krasnoff L, and Moshé SL.,1992.Recurrent status epilepticus in children. Ann Neurol 31:598-604.

13. Zaidel DW, Esiri MM, Oxbury JM.,1993. Regional differentiation of cell densities in the left and right hippocampi of epileptic patients. J.Neurol 240:322-325,

14. Vorhees CV, Williams MT., 2006. Morris water maze: procedures for assessing spatial and related forms of learning and memory. Nat Protoc 1(2):848-58.

15. McCormick DA, Shu Y, Hasenstaub A, Sanchez-Vives M, Badoual M, and Bal T.,2003. Persistent cortical activity: mechanisms of generation and effects on neuronal excitability. Cereb Cortex 13(11):1219-31.

16. Ahmad M.,2013. Protective effects of curcumin against lithium-pilocarpine induced status epilepticus, cognitive dysfunction and oxidative stress in young rats. Saudi Journal of Biological Sciences 20:155-162.

17. Alaa EA, Heba MM, Doaa ME, Azab SS.,2018. Rifampicin ameliorates lithium-pilocarpine-induced seizures, consequent hippocampal damage and memory deficit in rats: Impact on oxidative, inflammatory and apoptotic machinery. Biochemical Pharmacology 156;431-443.

18. Khalil ML.,2006. Biological activity of bee propolis in health and disease. Asian Pac J Cancer Prev 7(1):2231.

19. Scorcin JM., 2016.Biological properties and therapeutic application of propolis, Phytother Res 30:894-905.

20. Farooqui T, Farooqui AA.,2012. Beneficial effects of propolis on human health and neurological diseases. Front Biosci 1;(4): pp.779-93.

21. Alves de Lima RO, Said RA, Sforcin JM, Bankova V, Darros BR, Salvadori DMF.,2005. Modifying effect of propolis on dimethylhydrazine-induced DNA damage but not colonic aberrant crypt foci in rats".Environ mol mutagen 45:8-14.

22.Li L-Y, Li J-L,Zhang H-M,Yang W-M,Wang K,Fang Y, Wang Y. 2013. TGF $\beta 1$ treatment reduces Hippocampal damage, spontaneous Recurrent Seizures, And Learning memory deficits in Pilocarpine treated Rats. J Mol neurosci 0:109-123.

23. Druga R, Kubova H, Suchomelova L, Haugvicova R.,2003. Lithium/Pilocarpine status Epilepticus-induced neuropathology of piriform cortex and adjoining structures in rats is age-dependent. Physiology Res 52:251264.

24. Costa-Ferro ZSM, Soares MBP, de Borba Cunha F, de Freitas Souza BS,.Leal MMT, et al., 2014.Antiepileptic and neuroprotective effect of human umbilical cord blood mononuclear cells in pilocarpine-induced epilepsy mode. Cytotechnology 66:193-199.

25. Qashu F, Taiza H. Figueiredo TH, Aroniadou-Anderjaska V, Apland JP, Braga MFM. 2010. Diazepam administration after prolonged status epilepticus reduces neurodegeneration in the amygdala but not in the hippocampus during epileptogenesis. Amino Acids; 38(1): 189-197.

26. Emre S, Yilmaz Z, Oztürk F, Emre MH.,2009. Propolis prevents the effects of chronic alcohol intake on ocular tissues. Ophthalmic Res 42(3):147-51.

27. Morris R.,1984. Developments of a water-maze procedure for studying spatial learning in the rat. J Neurosci Methods 11: 47-60.

28. Suvarna SK, Layton C, Bancroft JD.,2012. Bancroft's Theory and Practice of Histological Techniques. 7th ed., Churchill Livingstone, London pp. 173-175).

29. Brywe, K. G., Leverin, A. L., Gustavsson, M., Mallard, C., Granata, R., Destefanis, S., ... \& Isgaard, J. (2005). Growth hormone-releasing peptide hexarelin reduces neonatal brain injury and alters Akt/glycogen synthase kinase-3 $\beta$ phosphorylation. Endocrinology, 146(11), 4665-4672).

30. Sharma, A. K., Jordan, W. H., Reams, R. Y., Hall, D. G., \& Snyder, P. W. (2008). Temporal profile of clinical signs and histopathologic changes in an F-344 rat model of kainic acid-induced mesial temporal lobe epilepsy. Toxicologic pathology, 36(7), 932-943).

31. Bertram EH.2009.Temporal lobe epilepsy: Where do the seizures really begin. Epilepsy Behav 14(1) 32-37.

32. Müller CJ, Bankstahl M, Gröticke I, Löscher W.,2009. Pilocarpine vs. lithium-pilocarpine for induction of status epilepticus in mice: development of spontaneous seizures, behavioral alterations, and neuronal damage. Eur J Pharmacol Oct 1;619 (1-3):15-24

33. Inokuchi Y,.Shimazawa M, Nakajima Y, Sueemori S, Mishima S, and Hara H.,2006. Brazilian Green propolis protects against retinal damage in vitro and in vivo., eCAM.;3(1) 71-77,

34. Ni J, Wu Z, Meng J, Zu A, Zhong X, Wu S, and Nakanishi H.,2017. the neuroprotective effect of Brazilian green propolis on neurodegenerative damage in human neuronal SH-SY5Y cells.Hindawi; Oxidative Medicine and Cellular Longevity, https:// doi.org/10.1155/2017/7984327.

35. Bankova V, Popova M, Trusheva B.,2018. the phytochemistry of the honeybee.Phytochemistry 155:1-11. 
36. Pasupuleti VR, Sammugan L, Ramesh N, and Gan SH.,2017.Honey, Propolis and Royal Jelly: A Comprehensive Review of their biological action and health benefits.Hindawi; Oxidative Medicine and Cellular Longevity, https:// doi.org/10.1155/2017/1259510

37. Contreras-Garcia IJ, Pichardo-Macias LA,Santana -Gomez CE, Sanchez-Huerta K, Ramirez-Hernandez R, Gomez-Gonzalez B,Rocha L, Torreblanca JMG .2018 .differential expression of synaptic vesicle protein 2A after status epilepticus and during epilepsy in lithium-pilocarpine model. Epilepsy\&Behavior 88283-294.

38. Faure JB ${ }^{1}$, Akimana G, Carneiro JE, Cosquer B, Ferrando A, Geiger K, Koning E, Penazzi L, Cassel JC, Nehlig. A.,2013. A comprehensive behavioral evaluation in the lithium-pilocarpine model in rats: effects of carisbamate administration during status epilepticus. Epilepsia 54(7):1203-13. 